\title{
CONTRIBUIÇÃO DOS SOFTWARES EDUCATIVOS NA CONSTRUÇÃO DO CONHECIMENTO DE FORMA LÚDICA
}

\author{
THE CONTRIBUTION OF EDUCATIONAL SOFTWARES IN THE \\ CONSTRUCTION OF KNOWLEDGE IN A PLAYFUL MANNER
}

\author{
LA CONTRIBUTION DES LUDICIELS ÉDUCATIFS \\ DANS LA CONSTRUCTION DU SAVOIR
}

CONTRIBUCIÓN DE LOS SOFTWARES EDUCATIVOS EN LA CONSTRUCCIÓN DEL CONOCIMIENTO DE FORMA LÚDICA

\author{
Regina Cury* \\ Lina Cardoso Nunes **
}

\begin{abstract}
RESUMO
Esta pesquisa teve como objetivo verificar se o uso de softwares educativos, numa perspectiva lúdica, pode contribuir para a construção do conhecimento de crianças do Ensino Fundamental. Na pesquisa de campo foram feitas observaçôes de crianças na sala de informática e realizadas entrevistas semi-estruturadas com os professores e equipe pedagógica. O embasamento teórico se apoiou nas contribuiçôes de estudiosos como Papert, Piaget, Valente, Vigotski e Winnicott, entre outros. Os dados obtidos nas entrevistas foram submetidos à análise de conteúdo, tendo em vista os temas recorrentes, a saber: relação entre software e conteúdos, o jogo de regras, dimensão lúdica do jogo, os jogos como fonte de prazer, aprendizagem e conhecimento, mediação e interação. Os resultados mostraram que o uso de softwares educativos, de forma lúdica, é importante para a aprendizagem das crianças, tornam as aulas mais dinâmicas, favorecem a mediação entre professores e alunos, possibilitando a construção do conhecimento.
\end{abstract}

Palavras-chave: Softwares educativos. Atividades lúdicas. Construção do conhecimento.

* Mestre em Educação pela Universidade Estácio de Sá (2007), Rio de Janeiro - RJ. Professora de Informática Aplicada à Educação e Estágio Supervisionado I e II (reginacury@terra.com.br). A discussão aqui apresentada é um excerto da dissertação de mestrado (CURY, 2007).

** Doutora pela Universidade Federal do Rio de Janeiro (1990). Professora do Mestrado em Educação da Universidade Estácio de Sá, Rio de Janeiro - RJ (linanunes@brturbo.com.br). 


\section{INTRODUÇÃO}

Com os avanços tecnológicos, podemos observar que as mudanças estão se tornando cada vez mais presentes no nosso dia-a-dia, através da televisão, do rádio, da telefonia e também dos recursos da informática. As novas demandas trazem desafios para os profissionais da educação, especialmente para aqueles que atuam em escolas, tendo em vista a necessidade de rever as formas de interação professor-aluno-informação. De acordo com Moraes (2000, p. 23):

[...] a realidade da pedagogia dos meios modernos, cuja interação professor-aluno-informação deverá levar o indivíduo a aprender a pensar, a aprender a antecipar, a aprender a cultivar o espírito crítico e criativo, para que ele possa sobreviver num mundo onde inúmeras informaçóes estarão disponíveis, e que precisam ser criticamente avaliadas, para serem transformadas em conhecimentos.

Nesse contexto, o computador representa mais que uma máquina de ensinar; seu uso na educação, segundo Valente (1993), pode promover a aprendizagem do educando e ajudar na construção do processo de conceituação e no desenvolvimento de habilidades importantes para que ele participe da sociedade do conhecimento. ${ }^{1}$ Para que isso ocorra, é preciso levar em consideração aspectos pedagógicos e sociais ao se inserir a informática nos processos educacionais.

Lévy (1993) argumenta que a integração demanda uma escola que transcenda seus muros, rompendo velhos paradigmas, e adote uma prática pedagógica contextualizada e dinâmica, o que não pode ser feito abruptamente.

Para o autor, com a sociedade do conhecimento, surge uma mudança de paradigma, na qual formar o indivíduo pressupóe propiciar-lhe condições de se tornar um sujeito investigador e pesquisador atuante para construir seu conhecimento, abandonando a posição de receptor passivo. Juntos, professor e aluno buscam propostas para acessar a informação, analisar, refletir e construir o conhecimento com autonomia, procurando soluçōes, criando um ambiente de aprendizagem favorável à discussão e à reflexão.

A verdadeira função educacional não deve ser a de ensinar, mas sim a de criar condições de aprendizagem. $\mathrm{O}$ professor precisa deixar de ser o repassador de conhecimento e passar a ser o criador de ambiente de aprendizagem e o facilitador do processo de desenvolvimento intelectual do aluno (VALENTE, 1993, p. 6).

Diante do contexto de transformação e de novas exigências em relação ao aprender, as mudanças não dizem respeito à adoção de métodos diversificados de jogos e/ou brincadeiras no computador, mas sim à atitude diante do conhecimento e da aprendizagem, e da nova concepção de Homem, de Mundo e de Sociedade. Isso significa que o professor terá papéis diferentes a desempenhar e que necessitará de novos modos de 
formação que possam prepará-lo para o uso pedagógico do computador, assim como para refletir na prática e sobre sua prática (SHÖN, 1992).

A adoção das novas tecnologias que promovam significativamente a aprendizagem, particularmente as computacionais, requer interação, participação, colaboração e a consciência de que o conhecimento implica um processo de construção. Assim, o indivíduo constitui-se no agente ativo de seu próprio conhecimento e, com base em suas experiências em diferentes contextos, constrói significados na representação da realidade. De acordo com Moran (1998), as tecnologias são extensões da mente humana.

As tecnologias da informação e da comunicação têm sido utilizadas em larga escala, em diversas instâncias, implicando mudanças nos diferentes ambientes sociais, proporcionando facilidades e progressos, especialmente no que diz respeito ao seu papel no aprendizado do educando. Com essas mudanças, o espaço para o jogo e a brincadeira tem se ampliado em relação a décadas atrás, e os educadores passam a perceber que, ao brincar, a criança está estabelecendo relações com o outro e, ao mesmo tempo, diferenciando-se deste, o que pode favorecer o seu desenvolvimento, expressando uma realidade familiar ou social, criando e seguindo regras; enfim, está experimentando, explorando e conhecendo o mundo que a cerca.

Dependendo da visão educacional e da forma como o computador é usado, a informática educativa tem assumido diversos significados. Valente (1993) enfatiza a necessidade de o professor conhecer as potencialidades educacionais da tecnologia para poder mesclar atividades de ensino e aprendizagens informatizadas ou não.

$\mathrm{O}$ uso da informática na educação tem progressivamente sido aplicado no processo ensino-aprendizagem, mediante o desenvolvimento de atividades lúdicas apoiadas em softwares educacionais, ${ }^{2}$ capazes de tornar a prática educacional e a relação professoraluno mais prazerosa.

No entanto, Papert (1994) alerta que atividades lúdicas não constituem apenas momentos de diversão; isso porque existem estratégias a serem observadas durante as brincadeiras. Na opinião de Vigotski (1989, p. 54), as atividades lúdicas não estão simplesmente ligadas ao prazer: "definir o brinquedo como uma atividade que dá prazer à criança é incorreto por duas razôes. Primeiro, muitas atividades dão à criança experiências de prazer muito mais intensas. E segundo, existem jogos nos quais a própria atividade não é agradável”.

Como atividade lúdica, os jogos têm como objetivo o entretenimento; porém, podem ser utilizados com fins educacionais, dependendo do contexto em que sejam inseridos, configurando excelentes oportunidades para desenvolver habilidades físicas e mentais importantes nos alunos, sobretudo os das séries iniciais, como, por exemplo, os jogos de percepção visual, coordenação viso-motora, atenção, e raciocínio lógico.

Cabe sinalizar que encontramos várias teses e dissertaçôes desenvolvidas no Ensino Fundamental que tratam de alguns aspectos incluídos no presente artigo. Dentre elas, 
podem ser citadas as seguintes teses de doutorado: Sidericoudes (2004); Pimentel (2004) e Gama (2007). Como dissertações de mestrado, destacamos Tomaz (2005) e Brito (2000). No entanto, nenhuma delas aborda a temática do estudo em foco.

Assim, o presente artigo tem como objetivo geral analisar se o uso de softwares educativos, numa perspectiva lúdica, pode contribuir para a construção do conhecimento. Os objetivos específicos buscam identificar as estratégias utilizadas pelos professores na criação de ambientes de aprendizagem, com a aplicação de softwares educativos, e analisar como os softwares educativos contribuem para a construção do conhecimento de forma lúdica.

\section{OS JOGOS NO DESENVOLVIMENTO INFANTIL COMO ALTERNATIVA DE ENSINO}

O jogo está tão impregnado no nosso cotidiano, que, às vezes, parece que sempre foi valorizado como recurso/instrumento educativo, o que não é verdadeiro. Segundo Kishimoto (2006), uma característica do século XVIII é a popularização dos jogos educativos. Antes restritos aos príncipes e nobres, tornam-se, naquela época, veículos de divulgação, crítica e doutrinação popular. Utilizados para o desempenho de papéis, difusão de idéias e crítica de personagens, tais jogos penetram no cotidiano popular.

Pesquisas de caráter interdisciplinar demonstram que o ato de brincar e outros comportamentos do ser humano sofrem intensa influência da cultura na qual está inserida a criança. Preceptores da época utilizam as imagens publicadas para criar jogos destinados à educação dos príncipes e nobres. $\mathrm{O}$ clima de efervescência científica favorece a publicação de inúmeras obras que valorizam o aprendizado das ciências, por intermédio de novas metodologias. "É ainda no século XVIII que nasce a concepção de infância construída ao longo de cinco longos séculos e postulada por Rousseau, em seu livro Emílio, como a necessidade de uma educação ajustada à natureza infantil” (idem).

A infância passa a ser entendida como período especial na evolução do ser humano, batizada por Ariès (1981), posteriormente, como "sentimento de infância", trazendo em decorrência a adoção de práticas educativas que prevalecem até hoje: a criança passa a ser vestida de acordo com sua idade, brinca com cavalinhos-de-pau, peões e passarinhos e tem permissão para se comportar de modo distinto do adulto. Abre-se, assim, um espaço propício ao nascimento da Psicologia Infantil, que desabrocha, no século XX, com a produção de pesquisas e teorias que discutem a importância do ato de brincar para a construção de representações infantis.

Estudos e pesquisas de caráter psicogenético, desenvolvidas principalmente por Bruner (1975), Piaget (1972), e Vigotski (1989), entre outros, fecundam relevantes pressupostos para a construção de representações infantis relacionadas às diversas áreas do conhecimento, influenciando algumas atividades curriculares dos novos tempos. 
Complementam tais estudos uma especificidade que pode se refletir nas condutas lúdicas, fazendo emergir a valorização dos brinquedos e brincadeiras tradicionais como fonte de conhecimento e de desenvolvimento infantil. De acordo com Bruner (1978), brincadeiras infantis estimulam a criatividade, no sentido de conduzir à descoberta das regras e colaborar com a aquisição da linguagem.

Embora o século XX seja reconhecido como uma época de importantes avanços nos estudos dessa questão, não se pode deixar de lembrar que Froebel, em 1769, já reconheceu o caráter educativo do jogo, partindo do pressuposto de que, manipulando e brincando com materiais como bola, cubo e cilindro, montando e desmontando cubos, a criança estabelece relaçôes matemáticas e adquire as primeiras noçôes de Física e Metafísica. "Ele aliou a utilização de materiais educativos, tais como o recorte, a colagem, a tecelagem e a dobradura, para elaborar uma proposta curricular que enfatizava a relevância do brinquedo na aprendizagem" (FROEBEL apud KISHIMOTO, 2006, p. 34).

No início do século XX, a médica italiana Maria Montessori elabora uma metodologia de ensino destinada às crianças deficientes, empregando materiais criados por Itard $^{3} \mathrm{e}$ Séguin, ${ }^{4}$ com o objetivo de implementar a educação sensorial. Sua obra, traduzida em Língua Portuguesa como Pedagogia Científica (1965), lista esses materiais e explica como utilizá-los. Conforme Oliveira (2002, p. 75) ilustra, seu material didático "buscava fazer um detalhamento rigoroso do conteúdo a ser trabalhado com as crianças e previa exercícios destinados a desenvolver, passo a passo, as diversas funções psicológicas". Embora as idéias de Montessori tenham chegado ao Brasil desde os primórdios do século passado, sua expansão ocorre mais tarde, quando começa a ser adotada pelas escolas particulares destinadas à elite.

O crescente interesse pelo jogo e sua valorização chegam ao Brasil na década de oitenta, com o advento das brinquedotecas, a criação de associações, a multiplicação de congressos, o aumento da produção científica sobre o tema e o interesse crescente dos empresários em aumentar seu faturamento, investindo em novos produtos.

De acordo com Rizzi e Haydt (1997), a importância do jogo na educação é enfatizada principalmente nos momentos de crítica e reformulação da educação, quando são lembrados como alternativas interessantes para a solução dos problemas da prática pedagógica. Geralmente, em períodos de contestação, de inquietações políticas e crises econômicas, aumentam as pesquisas e os estudos em torno dos jogos.

A especialização excessiva dos 'brinquedos educativos', dirigidos ao ensino de conteúdos específicos, está retirando o jogo de sua área natural e eliminando o prazer, a alegria e a gratuidade, ingredientes indispensáveis à conduta lúdica (KISHIMOTO, 2008, p. 44).

$\mathrm{Na}$ concepção piagetiana, os jogos consistem num exercício das ações individuais já aprendidas, gerando sentimento de prazer pela ação lúdica e pelo domínio sobre as ações. 
Têm dupla função: consolidar os esquemas já formados e dar prazer ou equilíbrio emocional à criança (FARIA, 1995).

Através da brincadeira, a criança se projeta no mundo dos adultos, aprendendo novas significações, separando o objeto real do seu significado e alcançando a definição funcional de conceitos ou objetos, além de desenvolver formas de comportamentos socialmente constituídos. Vigotski (1989) considera que o lúdico influencia enormemente o desenvolvimento da criança. Por meio do jogo a criança aprende a agir, sua curiosidade é estimulada, adquire iniciativa e autoconfiança, proporciona o desenvolvimento da linguagem, do pensamento e da concentração.

Os jogos possuem certas características que podem ser resumidas como: (a) a capacidade de absorver o participante de maneira intensa e total (clima de entusiasmo, sentimento de exaltação e tensão seguido por um estado de alegria e distensão); (b) o envolvimento emocional; (c) a atmosfera de espontaneidade e criatividade; (d) a limitação de tempo: o jogo tem um estado inicial, um meio e um fim; isto é, tem um caráter dinâmico; (e) a possibilidade de repetição; (f) a limitação do espaço: o espaço reservado seja qual for a forma que assuma é como um mundo temporário e fantástico; (g) a existência de regras; ou seja, cada jogo se processa de acordo com certas regras que determinam o que 'vale' ou não dentro do mundo imaginário do jogo, o que auxilia no processo de integração social das crianças (PIAGET, 1978).

Muito embora os jogos possam ser classificados de diferentes formas, Piaget elaborou uma 'classificação genética baseada na evolução das estruturas'. Agrupou-os em três grandes categorias, que correspondem às três fases do desenvolvimento infantil: fase sensório-motora, fase pré-operatória e fase das operações concretas.

$\mathrm{Na}$ fase sensório-motora (do nascimento até os dois anos, aproximadamente) a criança brinca sozinha, sem utilização da noção de regras. Os jogos de exercício sensório-motor iniciam a atividade lúdica. Sua finalidade é o próprio prazer do funcionamento. Esses exercícios consistem em repetição de gestos e movimentos simples, como correr, pular, emitir sons.

$\mathrm{Na}$ fase pré-operatória (dos dois aos cinco ou seis anos, aproximadamente), as crianças adquirem a noção da existência de regras e começam a jogar com outras crianças. Também brincam muito com jogos de 'faz-de-conta', os chamados jogos simbólicos, cujo objetivo é a satisfação do eu por meio de uma transformação do real em função dos desejos. A criança tende a reproduzir nesses jogos as relaçôes predominantes no seu meio ambiente, e assimilar, dessa forma, a realidade e a maneira de se auto-expressar. Através do 'faz-de-conta' realiza sonhos e fantasias, e revela medos e ansiedades, expressando suas tensões e frustraçôes.

$\mathrm{Na}$ fase das operações concretas (dos sete aos 11 anos, aproximadamente), caracterizada pela aprendizagem dos jogos coletivos, a preferência é por jogos de regras, como futebol, damas, entre outros. Segundo Piaget (1978), nessa faixa etária, o simbolismo 
tende a desaparecer, dando lugar, com mais freqüência, a desenhos, trabalhos manuais, construções com materiais didáticos, representaçôes teatrais, entre outros.

O jogo de regras continua durante toda a vida do indivíduo, a exemplo dos esportes, jogo de xadrez, baralho e RPG. Nesse sentido, as concepções sócio-interacionistas partem do pressuposto de que a criança aprende e desenvolve suas estruturas cognitivas ao lidar com o jogo de regras (KISHIMOTO, 1999, p. 79). Uma característica básica do jogo de regras é a existência de um conjunto de leis impostas pelo grupo, cujo descumprimento é normalmente penalizado, o que acirra a competição entre os indivíduos. A existência de parceiros e um conjunto de regras o caracterizam como uma atividade social. Esse tipo de jogo aparece quando a criança abandona a fase egocêntrica, o que possibilita desenvolver os relacionamentos afetivo-sociais.

A imaginação em ação ou brinquedo, de acordo com Vigotski (1991), é a primeira possibilidade de atuação da criança numa esfera cognitiva que lhe permite ultrapassar a dimensão perceptiva motora do comportamento.

Kishimoto (1999) reitera que, no desenvolvimento das crianças, é evidente a transição de uma forma para outra, através do jogo, que é a imaginação em ação. A criança precisa de tempo e de espaço para trabalhar a construção do real pelo exercício da fantasia.

Nessa perspectiva, Piaget (1978) afirma que, na criança, a imaginação criadora surge em forma de jogo, instrumento primeiro de pensamento no enfrentamento da realidade. O jogo sensório-motor se transforma em jogo simbólico, ampliando as possibilidades de ação e compreensão do mundo. O conhecimento deixa de estar preso ao aqui e agora, aos limites da mão, da boca e do olho e o mundo inteiro pode estar presente dentro do pensamento, uma vez que é possível 'imaginá-lo', representá-lo com um gesto no ar, no papel, nos materiais, com sons, com palavras.

Representar é dar forma às experiências humanas significativas: tornar novamente presente, presentificar vivências que, por sua importância, mereçam ser permanentemente lembradas. $\mathrm{O}$ imaginário não se confunde com o real; ele é instrumento para compreensão e tomada de consciência do real (KISHIMOTO, 1999, p. 52).

Vigotski (1989) enfatiza a influência do contexto social na formação da inteligência; portanto, no desenvolvimento do sujeito. Neste sentido, valoriza o fator social, mostrando que, nas brincadeiras dos jogos de papéis, a criança cria uma situação imaginária, incorporando elementos do contexto cultural, adquiridos por meio da interação e da comunicação. Para esse autor, a questão fundamental do jogo é que ele propicia a zona de desenvolvimento proximal (ZPD); ou seja, o jogo é o responsável pelo impulso do desenvolvimento dentro dessa zona. As brincadeiras são aprendidas no contexto social, tendo o suporte de seus pares e adultos. Esses jogos contribuem para o surgimento do papel comunicativo da linguagem, aprendizagem das convenções sociais e a aquisição de habilidades sociais. 
A teoria Vigotskiniana tem como perspectiva o homem como sujeito total, enquanto mente e corpo, organismo biológico e social, integrado em um processo histórico. A partir de pressupostos da epistemologia genética, sua concepção de desenvolvimento é concebida em função das interações sociais e respectivas relações com os processos mentais superiores, que envolvem mecanismos de mediação. As relações homem-mundo não ocorrem diretamente; são mediadas por instrumentos ou signos fornecidos pela cultura (VIGOTSKI, 1989). O conceito de mediação decorre da idéia de que o homem tem a capacidade de operar mentalmente sobre o mundo, isto é, de representar os objetos e fatos reais através de seu sistema simbólico, o que lhe dá a possibilidade de operar tanto com objetos ausentes como com processos de pensamentos imaginários.

Vigotski (1989, p. 44) afirma que "a linguagem e o desenvolvimento sociocultural determinam o desenvolvimento do pensamento". Assim, o sistema simbólico fundamental na mediação sujeito-objeto é a linguagem humana, instrumento de mediação verbal do qual a palavra é a unidade básica.

A fala humana, além de ser um instrumento de comunicação verbal e contato social, ainda funciona de forma completamente integrada ao pensamento: organiza os elementos do mundo, nomeia-os e os classifica em categorias conceituais, de acordo com os símbolos de determinada linguagem. Portanto, a palavra, como categoria cultural, é parte integrante do desenvolvimento, funciona como intercâmbio social e como pensamento generalizante, ao caracterizar uma classe de objetos do mundo.

Para compreender o indivíduo, é necessário compreender as relações sociais que se estabelecem no ambiente em que ele vive. Isso significa compreender as relaçóes entre atividades práticas e trabalho, no sentido de que a atividade prática é transformadora e institucionalizada, envolve dialeticamente o trabalho manual e os processos comunicativos (CASTORINA, 1996). Atividade prática não se restringe à ação sobre os objetos, mas, sobretudo, ao posicionamento do homem em relação ao mundo historicamente organizado.

Sujeito e objeto são criados em contínua interação que se realiza na atividade prática. O sujeito que atua no mundo é um ser social, histórico e cultural, que incorpora normas e sistemas simbólicos culturalmente construídos; transforma-os e transforma-se numa relação dialética, em que a atividade envolve desde o que inicialmente ocorre como atividade externa, através dos instrumentos mediadores, até a "sua transformação por uma atividade mental" (CASTORINA, 1996, p. 30).

Assim, a análise do processo de desenvolvimento não deve se concentrar em seus resultados ou produtos, mas sim em todo o processo; deve acompanhar suas fases, buscar sua natureza, sua essência e suas causas dinâmicas.

Para Vigotski (1993), o indivíduo interioriza formas de funcionamento psicológico, apreendidas através da cultura, mas, ao assumi-las, torna-as suas; reelabora-as ou as recria, e as incorpora às suas estruturas. $\mathrm{O}$ indivíduo constrói seus próprios significados 
e os emprega como instrumentos de seu pensamento individual para atuar no mundo. De acordo com o autor, o lúdico influencia enormemente o desenvolvimento da criança. É através do jogo que a criança aprende a agir, sua curiosidade é estimulada, adquire iniciativa e autoconfiança, proporciona o desenvolvimento da linguagem, do pensamento e da concentração.

A teoria de Vigotski (1989) enfatiza que a aprendizagem se encontra envolvida no desenvolvimento histórico-social do sujeito e que esse desenvolvimento não ocorre sem a presença da aprendizagem, que é a fonte do desenvolvimento. Assim, os processos de desenvolvimento e de aprendizagem não são coincidentes; o desenvolvimento segue a aprendizagem e esta origina o surgimento da zona proximal de desenvolvimento (ZPD). A aprendizagem origina-se na ação do aluno sobre os conteúdos específicos e sobre as estruturas previamente construídas que caracterizam seu nível real de desenvolvimento no momento da ação. "A intervenção é realizada no sentido de orientar o desenvolvimento do aluno para que ele possa apropriar-se dos instrumentos de mediação cultural" (CASTORINA, 1996, p. 121).

A informática educativa, ferramenta de grande importância no processo ensinoaprendizagem e cada vez mais presente nos ambientes escolares, nas últimas décadas tem passado por inúmeras transformações.

De acordo com Passerino (2001), sua utilização mais freqüente dá-se através dos softwares educativos; ou seja, do conjunto de recursos da informática usados em contexto de aprendizagem, que deve permitir, aos alunos, a construção de significados e representações, de forma coletiva e individual, independentemente do contexto escolar em que se insere, possibilitando a colaboração entre professor-alunos e alunos-alunos.

No entanto, a escolha do software educacional é algo complexo, que envolve fatores pedagógicos de integração curricular e de alinhamento ao público-alvo. Isso implica que essa escolha e a maneira de utilizá-lo sejam sustentadas numa proposta significativa, tendo em vista a construção e a organização do raciocínio, a fim de que possa refletir a aprendizagem dos indivíduos.

\section{AS VOZES DOS ENTREVISTADOS}

Para atender aos objetivos da presente pesquisa, foi aplicado inicialmente um questionário para caracterização dos 18 professores da instituição ${ }^{5}$ e posteriormente realizadas entrevistas semi-estruturadas junto aos professores do Ensino Fundamental, tendo participado 11 professores do primeiro ao quarto ano, com um roteiro previamente preparado, cujo foco foi voltado para os objetivos da pesquisa, especialmente quanto à contribuição das atividades do computador para a construção do conhecimento e as relações encontradas entre os softwares educativos e os conteúdos da aprendizagem, propostos pelos professores. Os dados obtidos nas entrevistas foram analisados de acordo 
com a análise temática (BARDIN, 2003). Os seguintes temas foram emergentes nas vozes dos entrevistados: (a) dimensão lúdica do jogo; (b) aprendizagem e conhecimento; (c) relação entre softwares educativos e conteúdos curriculares; (d) jogo de regras; (e) mediação e interação; (f) os jogos como fontes de prazer.

O primeiro tema relaciona-se diretamente ao objeto de nosso estudo; é a dimensão lúdica do jogo. Os jogos favorecem o desenvolvimento infantil, propiciando brincadeiras que estimulam o raciocínio lógico e despertam a curiosidade da criança. As transcrições seguintes explicitam bem o tema em foco.

P 1 - Os jogos ajudam as situações de aprendizagem na medida em que as crianças podem usar o computador e de uma forma lúdica aprender aquilo que você quer que ela aprenda, tome conhecimento. (...) no computador a criança pode brincar.

P 2 - As atividades com o computador podem favorecer o lúdico. Quer ver? Em geometria tenho um ótimo exemplo. A gente tem aqui um programa chamado Poli. É um programa que a gente baixa da Internet, é um programa free. O aluno consegue, através desse programa, ver todas as formas geométricas em várias posiçôes; vamos dizer assim: ele trabalha bastante a situação lúdica da peça em si, tamanho, formato e medida.

P 3 - Eu acho que os jogos são fundamentais para o desenvolvimento infantil. Desde bebê, a criança joga dentro do útero; brinca com ele mesmo. Tem estudos mostrando que ele brinca com o cordão, como ele brinca com o saco que o envolve, e assim por diante. Ele vai brincando e toda aprendizagem que se dá dessa forma lúdica é mais divertida, mais fácil, mais interessante para a criança.

P 6 - Eu acho que se você criar condições para as crianças usarem o computador através do lúdico, eu acho que ele favorece a aprendizagem sim, porque, como eu falei, é uma linguagem da criança, é uma linguagem mais dos jogos que favorece a questão do prazer da criança de estar ali trabalhando com o computador.

P 7 - Totalmente, porque eles têm a questão da imagem, da cor, do movimento, da possibilidade de eles estarem mudando toda hora; são recursos, são muitos recursos, então é lúdico.

P 9 - Atividade com softwares educativos é um acréscimo, é mais uma coisa que ela pode usar na sua situação do dia-a-dia, na situação do brincar.

É no brincar que a criança expressa sua liberdade de criação. Para Winnicott (1975), a atividade lúdica está presente nas experiências socioculturais e criativas. O lúdico faz parte do desenvolvimento infantil na construção de saberes e nas atividades intelectuais imprescindíveis nas práticas educativas.

O segundo tema intitulado destacou aspectos sobre aprendizagem e conhecimento, apontando em direção às possibilidades que se apresentam para as crianças aprenderem na situação do jogo e mostrando como esses os recursos da informática podem auxiliar na construção do conhecimento. Indica também como a participação é estimulada e os 
diferentes ritmos de aprendizagem das crianças. Adiante, apresentam-se falas dos professores relacionadas a esse tema.

P 2 - Sem dúvida alguma, os jogos são importantíssimos; ajudam na construção do conhecimento; a informática permite sair um pouco da sala de aula, aquele negócio de papel e caneta; leva para o mundo novo. Isso ajuda pra caramba o raciocínio dos alunos. (...) Os jogos ajudam bastante os alunos a desenvolver o raciocínio lógico, porque, depois, quando eles entram em qualquer outro programa, ou qualquer outro site, já sabem, por dedução, em quais botôes entrarem, não pelo jogo em si, mas pela ferramenta.

P 3 - Eu acho que o computador é um instrumento maravilhoso para que a criança possa ir interagindo e fazendo, na velocidade dela, no ritmo dela, os passos da aprendizagem; então, por ser instrumento individual nesse momento a velocidade de cada um é respeitada. Por esse ponto, acho favorável e muito interessante as crianças terem essa possibilidade de evoluir no seu ritmo.

P 6 - Olha, eu acho que o computador, a informática, é uma ferramenta que a criança tem que conhecer no mundo de hoje; então, acho que, já a partir daí, o jogo facilita esse conhecimento, porque ela vai estar aprendendo de uma forma prazerosa, com uma linguagem que ela entende, que ela joga.

P 7 - Os jogos estimulam muito a criança em situaçōes concretas a entenderem as questōes da aprendizagem e poderem trocar também, com seus pares, situaçōes de aprendizagem.

P 11 - Os softwares poderiam ser muito mais utilizados se eles tivessem uma qualidade melhor. Em geral, os softwares trabalham num tipo de pensamento que exige repetição, memorização e fixação, e não é esse o modelo de aprendizagem que a gente trabalha; então, o software educativo tem que propor alguma coisa que se diferencie do tradicional.

Essas falas têm respaldo na colocação de Valente (1999), quando aponta o computador como alternativa para a criação de ambientes de aprendizagem. Entretanto, como enfatizam os respondentes, torna-se necessário uma avaliação prévia desses softwares, que devem ser estimulantes, desafiadores e significativos, a fim de que os objetivos possam ser alcançados.

O computador constitui uma experiência concreta para a criança, o que orienta para o pensamento de Freire (1980), que enfatiza a importância para a aprendizagem, favorecida quando os sentidos estão envolvidos: a visão, a audição, o tato, por exemplo.

Assim, "qualquer situação de aprendizagem com que a criança se defronta na escola tem sempre uma história prévia" (VIGOTSKI, 2003, p. 110), uma vez que o aprendizado começa bem antes da freqüência ao ambiente escolar.

O terceiro tema voltado para as Relações entre Softwares Educativos e os Conteúdos Curriculares se volta à possibilidade de softwares educativos se relacionarem aos conteúdos das aulas, em diferentes matérias: Português, Matemática, Geografia, Ciência, 
e outras. Também é ressaltado, pelos participantes, o papel de determinados jogos para o raciocínio lógico da criança.

Transcrevemos, a seguir, as falas dos professores relacionadas ao tema.

P 1 - Esse ano a gente trabalhou com software de matemática de um site de uma escola inglesa que trabalha com as quatro operaçôes com pirâmide mágica. É super legal e eles adoraram. A gente estava usando também o site do IBGE, aquele de 7 a 12 anos; e volta e meia a gente faz pesquisa na rede para selecionar informaçôes para o trabalho.

P 3 - Dependendo do jogo, a gente o relaciona à matéria que se está trabalhando. Criamos um joguinho especifico tirando a idéia do Máster, que já existe no mercado, associando-o à Matemática, Geografia, Ciências, Historia e até Português.

P 5 - Eu acho que ele também contribui, porque quando a gente quer trabalhar alguma coisa de mapa, de localização, de fazer tabelas da multiplicação, a gente usa o laboratório de informática.

No sentido de melhorar sua prática e incorporar novas estratégias de ensino, é importante que o professor se aproprie do lúdico, ao inserir os conteúdos em sala de aula, já que, por meio das brincadeiras, a criança aprende com mais eficácia.

Brougère (1995) ressalta que é por meio das brincadeiras que as crianças apropriamse dos conteúdos e interiorizam o discurso externo, construindo sua compreensão.

Por sua vez, Rego (2003, p.131) afirma que "brincando a criança consegue introduzir-se na cultura dos grupos com os quais interage e nela atuar estabelecendo trocas; apropriar-se de noçôes ou conceitos dos quais ainda não tinha se apropriado de todo".

$\mathrm{O}$ quarto tema recorrente refere-se ao jogo de regras em que os participantes falam das perspectivas de aprendizagem, por meio dos jogos, inclusive das regras que são aprendidas no decorrer dessas atividades, e como podem ajudar no convívio social. Abaixo estão transcritas as falas dos participantes sobre esse tema:

P 3 - Através dos jogos as crianças aprendem muito; aprendem como se relacionar; aprendem algumas regras e, dependendo dos jogos que elas jogarem, vão apreendendo também aspectos referentes aos conteúdos curriculares.

P 4 - Acho que os jogos, pelo menos para essa faixa etária, estão constantemente presentes na vida da criança. Através dos jogos a gente pode trabalhar a questão das regras no grupo, o respeito ao outro, as relaçóes de poder, que possivelmente acontecem na turma.

P 6 - Eu acho que os jogos são atrativos naturais. Através dos jogos você pode desenvolver o raciocínio, criar e trabalhar regras; fora o interesse das crianças, que é muito grande.

P 9 - São várias questões na aprendizagem, mas o que eu vejo muito quando observo as crianças jogarem são as questôes das regras. Quando eles constroem as regras podemos ver um convívio social, o respeito pelo outro. Durante o jogo podemos ver como ele interage com o amigo socialmente. 
P 10 - Os jogos, além de proporcionarem vários tipos de aprendizagem, como, por exemplo, a matemática, também trabalham as regras. As crianças têm que respeitar as regras dos jogos e isso dá para elas um limite, onde ela tem que trilhar para aceitar determinadas situaçóes. Para mim o principal papel é instigar e criar estratégias de resolução dos jogos, em geral.

Como expresso pelos entrevistados, os jogos são muito importantes para o desenvolvimento infantil. De acordo com Kishimoto (1999), é com os jogos de regras que a criança aprende a lidar com as adversidades em relação ao espaço, ao tempo e as escolhas. Para a concepção sócio-interacionista, as crianças aprendem e desenvolvem suas estruturas cognitivas ao lidar com jogos de regra.

É importante ressaltar que durante a observação um aluno não respeitou a regra de um jogo, e pulou de fase, chegando ao final do jogo sem cumprir as etapas previstas. Os colegas que estavam ao seu lado não aceitaram tal atitude, fazendo-o rever e refletir sobre a importância de seguir as regras, mostrando-lhe que não era correto o que havia feito. Após dialogar com os colegas, o referido aluno reiniciou o jogo e obedeceu às regras nele existentes. Piaget (1978) ratifica essa questão ao se referir à importância da existência das regras, que determinam o que vale ou não, no imaginário mundo do jogo.

$\mathrm{O}$ quinto tema indicou a mediação e interação na classe e sua relevância para a aprendizagem. De acordo com as respostas dos entrevistados, percebemos que a mediação professor-aluno abre espaços para experiências significativas no contexto do processo de construção do conhecimento.

P 1 - Bom, todo mundo gosta de jogar, especialmente as crianças, eu acho que com jogos você favorece a interação entre eles; através deles, a criança vai aprender, devido à possibilidade que ela tem de se relacionar com o outro; isso é importante para o desenvolvimento dela. (...) O professor o tempo todo está mediando alguma situação na escola, então, se ele está propondo um jogo, orientando o grupo, ele é o facilitador da interação entre o grupo e entre a criança e o jogo.

P 3 - O professor na verdade é um mediador; é o que proporciona que a criança entre em contato com esses jogos, com essas experiências possibilitadas pela informática, para que ela possa tirar o máximo de proveito disso; e eu acredito também que ao final dos jogos o professor pode fazer uma espécie de reflexão sobre o que foi aprendido; e nesse momento, então, possibilita à criança arquivar, guardar dentro do cérebro dela tudo que ela aprendeu com aqueles jogos, com aquela experiência.

P 4 - Eu acho que o papel do professor é mediar às situações que ocorrem, podendo interferir nos momentos certos. É interessante que o professor deixe as situaçōes acontecerem nos jogos e interfira buscando soluções com as crianças, porque normalmente elas já trazem alguma coisa na cabeça, já tem alguma lógica ali; é importante o professor funcionar como mediador dessas situaçôes e interferir no sentido de auxiliá-las, no sentido de uma autonomia mesmo, dentro desse espaço dos jogos. 
A mediação professor-aluno opõe-se à prática de transmissão de conhecimento, em que o professor ensina e o aluno aprende. Nesse sentido, mediar é propor situações que levem o aluno a pensar, raciocinar, trocar, concluir e formular hipóteses e questóes para a construção do conhecimento.

O professor pode tornar-se o provocador do conhecimento. (...) Disponibilizará estados potenciais do conhecimento de modo que o aprendiz experimente a criação do conhecimento quando participa interferindo, agregando, modificando. Assim, o aprendiz deixa o lugar de recepção passiva de onde ouve, olha, copia e presta contas, para se envolver com a proposição do professor e/ou de outro aprendiz (SILVA, 2003, p. 55).

Desse modo, a intervenção do professor promove a interação, indispensável para o desenvolvimento do pensamento, e estimula o aprendiz a refletir sobre suas ações. Juntos, aluno e professor, num ambiente de camaradagem, cooperação e colaboração, podem transformar o conhecimento em um processo contínuo de construção. Sobre a interação, Kishimoto (1999, p. 110) afirma que:

Brincando as crianças aprendem a cooperar com os companheiros, a obedecer às regras do jogo, a respeitar os direitos dos outros, a acatar a autoridade, a assumir responsabilidades, a aceitar penalidades que lhes são impostas, a dar oportunidade aos demais; enfim, a viver em sociedade.

Portanto, cabe ao professor criar situações adequadas para provocar curiosidade na criança, possibilitando-lhe vivenciar situaçôes concretas com jogos diversos e múltiplas atividades que favoreçam a aprendizagem.

O sexto tema apresenta significativamente os jogos como fontes de prazer. De acordo com os resultados das entrevistas, percebemos que, na opinião dos professores, a natureza lúdica possibilitada pelos jogos, em geral, resulta em prazer, fascínio e atração, o que se pode constatar nas transmissões, abaixo.

P 1 - Bom, eu acho que o computador é um instrumento que por si só já causa um fascínio nas crianças. Aqui na escola na hora da informática eles adoram; ficam chateados quando a gente não sobe. Eu acho que você pode escolher os softwares que vão te ajudar na sala de aula; então, dependendo do que você quer trabalhar ou qual o seu objetivo, você pode escolher um software que vai te ajudar. (...) Como o computador é por si só um instrumento atrativo, você escolhendo um bom software ele pode propiciar uma boa situação de aprendizagem.

P 4 - Os softwares educativos são super-importantes no sentido de apresentarem atrativos que outras atividades não têm, como, por exemplo, as imagens e as animaçôes. A criança gosta de trabalhar com o computador; elas parecem que nascem com chip; a facilidade que elas têm de lidar com o computador é fantástica, um negócio que impressiona bastante. Então, eu acho que dependendo do contexto a gente pode utilizar os softwares, de forma prazerosa. 
P 5 - O professor está sempre proporcionando isso: o prazer; porque o lúdico é o prazer.

Você pode até associar a atividade lúdica puxando para a matéria mesmo, para o conteúdo pedagógico que você quer.

P 7 - O professor deve proporcionar situações de aprendizagem em que a criança se sinta mais interessada; que ela possa sentir prazer pelas atividades do dia-a-dia. Isso nem sempre é possível, mas a gente tenta.

As brincadeiras e os jogos fazem parte da vida do ser humano, proporcionando alegria e prazer. Papert (1994) afirma que, quando o aluno assume o comando de seu próprio desenvolvimento em tarefas que sejam significativas, o ato de aprender torna-se um ato de alegria e contentamento.

As falas transcritas evidenciam os aspectos relativos às possibilidades de criação de ambientes interativos de aprendizagem, a partir de softwares educativos, assim como os espaços que se apresentam para a dimensão lúdica na construção do conhecimento, propiciada pelos jogos, quando selecionados e alinhados, criteriosamente, aos objetivos inerentes aos diversos campos do conhecimento que se deseja explorar.

\section{CONSIDERAÇÕES FINAIS}

Nos dias atuais, o computador se torna cada vez mais presente no cotidiano escolar. Nesse contexto, é fundamental a reflexão sobre seu uso como recurso pedagógico a ser explorado no processo ensino-aprendizagem. Vive-se a 'era da informação' e, como conseqüência, a necessidade de se diversificar a experiência educacional, a fim de que os alunos possam desenvolver suas potencialidades, mediante uma educação dinâmica e desafiadora, que lhes possibilite aprender a aprender. E isso implica adquirir conhecimentos, habilidades e atitudes necessárias à obtenção e utilização eficaz das informaçōes, tendo em vista a construção do conhecimento.

As inovações tecnológicas não podem ser ignoradas pelas escolas e professores. Os softwares educativos podem dar prazer, divertir, enriquecer e explorar os conteúdos curriculares, se associados a estratégias de aprendizagem bem mediadas pelo professor, possibilitando, dessa forma, mudanças significativas na prática pedagógica.

A dimensão lúdica do jogo foi elemento recorrente nas falas dos participantes. Os entrevistados apontam o jogo como um instrumento de grande relevância no processo ensino-aprendizagem, pois permite, de forma dinâmica, o desenvolvimento de aspectos relacionados às áreas cognitivas, afetiva, social, lingüística e motora, entre outras. Apontam sua contribuição para a construção do pensamento crítico, da autonomia, da criatividade, e o exercício da cooperação e da responsabilidade. Na ótica dos professores, o jogo dá liberdade, revela a autonomia, a originalidade, permite inventar e expressar o próprio desejo, convivendo com as diferenças. Acreditam que os 
jogos de conteúdo educativo contribuem para o desenvolvimento do raciocínio, da interação social e do aprendizado. O processo é mais importante que o produto da atividade. A ludicidade implica querença. Embora a aquisição de conteúdos seja importante e desejável, a formação de atitudes adequadas prepara o aluno para a cidadania. Daí a necessidade de que os professores estejam envolvidos nesse processo.

No tema aprendizagem e conhecimento, os professores expressam que o emprego de softwares educativos como instrumento de uma aprendizagem significativa depende da forma como os mesmos são utilizados. Afirmam que é preciso que se faça uma avaliação preliminar desses produtos, de sua qualidade e de sua relação com o que se deseja pesquisar, selecionar e desenvolver; o que pressupõe planejamento. Simplesmente o uso do software não conduz a uma melhor situação de aprendizagem. Ele deve ser visto como um meio, uma complementação de apresentações formais, leituras e discussões dos conteúdos curriculares.

A relação de softwares educativos com os conteúdos curriculares desenvolvidos foi abordada pelos participantes. Os professores reconhecem que esses softwares podem enriquecer as aulas, tornando-as mais dinâmicas, favorecer a mediação professor-aluno e despertar o interesse dos alunos, desenvolvendo-lhes o gosto pela pesquisa e a capacidade de identificar, relacionar, comparar, avaliar diferentes eventos e fenômenos. Mas alertam para a necessidade de se conhecer bem esses produtos, cuja principal característica deve ser a de levar o aluno a construir conhecimento, relacionando-o com o conteúdo que se quer desenvolver. Isso implica, ainda, uma cuidadosa e planejada programação, anteriormente a sua aplicação.

Sobre o tema jogo de regras, os entrevistados apontam o jogo como um instrumento de grande relevância no processo ensino-aprendizagem, pois permite, de forma dinâmica, o desenvolvimento de aspectos relacionados às áreas cognitivas, afetiva, social, lingüística e motora, entre outras. Apontam sua contribuição para a construção do pensamento crítico, da autonomia, da criatividade, e o exercício da cooperação e da responsabilidade. Ressaltam a importância das regras, fundamentais para dar andamento às atividades, pois sem elas ninguém se diverte, o jogo não evolui. Para eles, o ato de jogar pressupõe reconhecer as regras, compreendê-las e identificar em que situaçôes devem ser usadas. Em alguns casos, podem ser modificadas, em comum acordo com todos os outros jogadores.

No tema mediação e interação, a figura do professor como facilitador da aprendizagem ganhou destaque. Softwares educativos, em especial os jogos, são vistos apenas como ferramentas a serviço da educação. Sua eficiência e eficácia dependem de alguém que possa analisá-los, criticamente, em relação aos objetivos pretendidos, aos conteúdos a serem desenvolvidos e à clientela a quem se destina. Nesse sentido, o papel do professor é o de mediador, o de orientador, acompanhando o desenvolvimento do aluno e intervindo, de forma positiva, sempre que necessário. 
Os jogos como fontes de prazer são aspectos muito enfatizados pelos respondentes, que afirmam que a escola centrada na transmissão de conteúdos não comporta a ludicidade, pois esta pressupõe o aleatório, o inusitado. $\mathrm{O}$ aluno tem uma participação ativa nas situações de ensino, sendo sujeito de seu aprendizado, e a espontaneidade e a criatividade são constantemente estimuladas. Ressalte-se que o lúdico não está presente apenas nos jogos, mas também nas brincadeiras ou qualquer outra atividade que permita a construção do conhecimento com a alegria e o prazer de quem quer fazer.

Assim, o uso das tecnologias, em especial dos softwares educativos, significa uma mudança na postura do professor, deixando para trás a educação bancária, definida por Freire (1969) como a passividade em relação aos conhecimentos, e caminha em direção a uma educação reflexiva e participativa, na qual o aluno é o sujeito do processo educativo, buscando e trocando informações, e construindo seus conhecimentos com autonomia, interatividade e satisfação.

\section{Notas}

1. A noção de "sociedade do conhecimento" (knowledge society) surgiu no final da década de 90. É empregada, particularmente, nos meios acadêmicos como alternativa que alguns preferem à "sociedade da informação" ou ainda "Sociedade em Rede" (CASTELLS, 2003).

2. Conjunto de recursos informáticos projetados com a intenção de serem usados em contexto de aprendizagem (MORELATTO, 2005).

3. Jean M. Gaspard Itard, médico e reeducador de surdos-mudos. Pioneiro da Educação Especial de deficientes mentais.

4. Edouard O Séguin, psiquiatra americano nascido na França. Organizou escolas para deficientes mentais no EUA.

5. Os resultados do questionário para caracterização dos professores constam da dissertação da qual se originou o artigo em foco.

\section{Referências}

ARIÈS, Phillipe. História social da criança e da família. Rio de Janeiro: Guanabara, 1981.

BARDIN, Laurence. Análise de conteúdo. Lisboa: Almedina, 2003.

BRITO, Sérgio Luiz. O computador como meio de comunicação pedagógica no ensino de química. Dissertação de Mestrado. Universidade de Brasília, Faculdade de Educação. Programa de PósGraduação em Educação, 2000.

BROUGÈRE, Gilles. Brinquedo e cultura. São Paulo: Cortez, 1995.

BRUNER, Jerome. Uma nova teoria de aprendizagem. Rio de Janeiro: Bloch, 1975.

. Acquiring the uses of language. Canadian Journal of Psychology. Old Chelsea, Quebec, v. 32, p. 204-218, 1978.

CASTELLS, Manuel. A sociedade em rede. Volume 1, São Paulo: Paz e Terra, 2003. 
CASTORINA, José Antonio. Piaget-Vigotski: novas contribuições para o debate. São Paulo: Ótica, 1996.

CURY, Regina Fátima. O uso de softwares educativos, numa perspectiva lúdica, para a construção do conhecimento. 2007. 104 folhas. Dissertação. Mestrado de Educação e Cultura Contemporânea, Universidade Estácio de Sá. Universidade Estácio de Sá - Unesa, Rio de Janeiro, RJ.

FARIA, Anália Rodrigues de. O desenvolvimento da criança e do adolescente segundo Piaget. 3. ed. São Paulo: Ática, 1995.

FREIRE, Paulo. Conscientização: teoria e prática da libertação: uma introdução ao pensamento de Paulo Freire. 3. ed. Trad.: Benedito Leite Cintra. São Paulo: Morais, 1980.

. A educação como prática da liberdade. Rio de Janeiro: Paz e Terra, 1969.

GAMA, Carmem Lúcia da. Método de construção de objetos de aprendizagem com aplicação de dados numéricos. Tese de Doutorado, Curitiba, UFPR, 2007.

KISHIMOTO, Tizuko Morchida. Jogo, brinquedo, brincadeira e educação. São Paulo: Cortez, 2006.

- O brinquedo na educação: considerações históricas. Disponível em: <http://www. cmariocovas.sp.gov.br/pdf/idéias_07_p039-045_c.pdf>. Acesso em: 1 set. 2008.

LÉVY, Pierre. As tecnologias da inteligência. O futuro do pensamento na era da informática. Trad.: Carlos Irineu da Costa. Rio de Janeiro: Editora 34, 1993.

MONTESSORI, Maria. Pedagogia científica: a descoberta da criança. São Paulo: Flamboyant, 1965.

MORAES, Raquel de Almeida. Informática na educação. 2. ed. Rio de Janeiro: DP\&A, 2000.

MORAN, José Manoel. Mudanças na comunicação pessoal. São Paulo: Paulinas, 1998.

MORELATTO, Claudete. Novas tecnologias da educação. Cinted: UFRGS, v. 3, n. 1, maio 2005. Disponível em: <www.cinted.ufrj.br>. Acesso em: 24 set. 2005.

OLIVEIRA, Zilma Moraes Ramos de. Educação infantil: fundamentos e métodos. São Paulo: Cortez, 2002.

PAPERT, Seymourt. A máquina das crianças. Porto Alegre: Artes Médicas, 1994.

PASSERINO, Liliana Maria. Informática na educação infantil: perspectivas e possibilidades. In: ROMAN, Eunilda Dias; STEYER, Vivian Edith (Orgs.). A criança de 0 a 6 anos e a educação infantil: um retrato multifacetado. Canoas-RS: 2001. Disponível em: <http://www.ulbra.tche.br/ -kborges/bib/li liana.PDF>. Acesso em: 10 dez. 2004.

PIAGET, Jean. Epistemologia genética. Petrópolis: Vozes, 1972.

. A formação do símbolo na criança. 3. ed. Rio de Janeiro: Livros Técnicos e Científicos, 1990.

PIMENTEL, Alessandra. Jogo e desenvolvimento profissional: análise de uma proposta de formação continuada de professores, Tese de Doutorado, 2004.

REGO, Teresa Cristina. Vigotski: uma perspectiva histórico-cultural da educação. Petrópolis: Vozes, 2003.

RIZZI, Leonor; HAYDT, Celia. Atividades lúdicas na educação da criança. 6. ed. São Paulo: Ática, 1997. (Série Educação). 
SHÖN, Donald. Formar professores como profissionais reflexivos. In: NÓVOA, Antonio. (Org.). Os professores e sua formação. Lisboa: Dom Quixote, 1992. p. 77-91.

SIDERICOUDES, Odete. Formação de profissionais docentes na preparação de jovens para o trabalho com TIC. Doutorado em Educação. Pontifícia Universidade Católica, São Paulo, 2004.

SILVA, Marco. Criar e professorar num curso online: relato de uma experiência. In: (Org.). Educação online. São Paulo: Loyola, 2003.

TOMAZ, Maria de Fátima. Softwares educacionais e o ensino de história: elementos para uma análise didática. Dissertação de Mestrado, Curitiba, UFPR, 2005.

VALENTE, José Armando (Org.). Computadores e conhecimento: repensando a educação. Campinas: Edunicamp, 1993.

VALENTE, José Armando. Mudanças na sociedade, mudanças na educação: o fazer e o acontecer. In: (Org.). O computador na sociedade do conhecimento. Campinas: Unicamp/Nied, 1999. p. 29-48.

VIGOTSKI, Liev Semionovitch. Linguagem, desenvolvimento e aprendizagem. São Paulo: Ícone, 1991.

. Pensamento e linguagem. 3. ed. São Paulo: Martins Fontes, 1989; 1993; 2003.

WINNICOTT, Donald Woods. O brincar e a realidade. Rio de Janeiro: Imago, 1975. 
The contribution of educational softwares in the construction of knowledge in a playful manner Abstract

This research aimed to verify if the playful use of educational softwares can contribute to the construction of children's knowledge in an elementary school. In field research, observations were made of children working in the computer room and semi-structured interviews were conducted with teachers and pedagogical staff. The background theory was based on the contributions of scholars such as Papert, Piaget, Valente, Vygotsky and Winnicott, among others. The data obtained from interviews were submitted to content analysis, considering recurring themes such as: relationship between software and content, game rules, playful dimension of the game, games as a source of pleasure, learning and knowledge, mediation and interaction. The results showed that the playful use of educational software is important to the learning of children, makes classes more dynamic, encourages mediation among teachers and students, enabling the construction of knowledge.

Keywords: Educational software. Recreational activities. Construction of knowledge.

\section{La contribution des ludiciels éducatifs dans la construction du savoir Résumé}

Cette recherche a eut comme objectif vérifier si l'utilisation de ludiciels éducatifs peut contribuer à la construction du savoir d'élèves de l'enseignement primaire. Dans le travail sur le champs, des observations d'enfants dans la salle d'informatique ont été faites et des entrevues semi-structurées ont été réalisées avec les maîtres et l'équipe pédagogique. Le fondement théorique s'est appuyé sur les contributions de chercheurs comme Papert, Piaget, Vygotsky et Winnicott, entre autres. Les données recueillies dans les entrevues ont été soumises à l'analyse de contenu, tenant compte des thèmes récurrents, à savoir : relation entre ludiciels et contenu, le jeu de règles, dimension ludique du jeu, les jeux comme source de plaisir, apprentissage et connaissance, médiation et interaction. Les résultats montrent que l'utilisation des ludiciels éducatifs est importante pour l'apprentissage des enfants, font comme quoi les leçons sont plus dynamiques, permettent la médiation entre maîtres et élèves, rendant possible la construction du savoir.

Mots clefs : Logiciels éducatifs. Activités ludiques. Construction du savoir.

\section{Contribución de los softwares educativos en la construcción del conocimiento de forma lúdica} Resumen

Esta investigación tubo como objetivo verificar si el uso de softwares educativos, en una perspectiva lúdica, puede contribuir para la construcción del conocimiento de niños en la enseñanza primaria. En el campo se observó niños en la clase de informática y fueron realizadas entrevistas semiestructuradas con profesores y equipo pedagógico. La base teórica se apoyó en las contribuciones de estudiosos como Papert, Piaget, Valente, Vygotsky y Winnicott, entre otros. Los datos obtenidos en las entrevistas fueron sometidos a análisis de contenido, enfocado los temas recurrentes: relación entre software y contenidos, el juego de reglas, dimensión lúdica del juego, los juegos como fuente de placer, aprendizaje y conocimiento, mediación e interacción. Los resultados apuntaron que el uso de softwares educativos, de forma lúcida, es importante para el aprendizaje de los niños, tornan las clases más dinámicas, favorecen la mediación entre profesores y alumnos, posibilitando la construcción del conocimiento.

Palabras-clave: Softwares educativos. Actividades lúdicas. Construcción del conocimiento.

Recebida I ${ }^{\mathbf{a}}$ versão em: 04.03.2008

Aceita $2^{\mathrm{a}}$ versão em: 19.12.2008 